\title{
Ascertaining the Sense of Safety in Urban Neighborhood Streets: The case of Kotahena, Sri Lanka
}

\author{
Sanduni Karunananda, Amanda Rajapakse, Rangajeewa Rathnayaka \\ Faculty of Architecture, University of Moratuwa, Sri Lanka
}

\begin{abstract}
Streets are primary elements through which the character of urban neighborhoods are experienced and expressed. The "sense of safety" in neighborhood streets is paramount to social and psychological wellbeing of its residents and visitors. The intention of this study was to explore environmental and social cues of a neighborhood, which evoke fear of crime, which will help designers to prevent the generation of such negative feelings and promote more safe and comfortable spaces in our cities. This study used interviews, group discussions and observations to identify fear-generating factors with a sample of participants in the multi ethnic neighborhood of Kotahena in Colombo, Sri Lanka. Field data was analyzed through visual documentation and photographic surveys. Moreover, group discussions, interviews and personal observations were used to synergize the study objectives. The findings inform that fear of crime on streets is influenced by both environmental and social cues to varying degrees. Feelings of fear were associated with gender, ethnicity and less familiarity with the place as participants were from an ethnic minority within the community. Literature has emphasized that fear of crime has a connection to actual crime locations. The research findings, however, indicate that fear of crime spots identified by the residents do not have a direct relationship to the actual crime locations.
\end{abstract}

Keywords: environmental cues, fear of crime spots, sense of safety, social cues

\section{Introduction}

Feelings of insecurity can influence individuals' behavior in space. It can have undesirable effects on people's psychology. Fear of crime may limit their mobility, hinder their outdoor activities and ultimately influence people's satisfaction of public places cities and regions. User perception of safety of the environment is an important indicator to assess walkability of our streets. In this context, it is the primary responsibility of planners and urban designers to design safe and convivial spaces in our urban settings. In order to design such places, planners and urban designers need to have a rich understanding of how a range of environmental and social clues influence feelings of safety or fear in city users. They also need to understand how social variable such as gender and ethnicity effect on fear of crime of people in public spaces. Little research, however, has been done in urban areas in Sri Lanka relating to sense of safety or fear of crime. Moreover, there is a lesser understanding about feelings of safety of people who live in multi-ethnic neighborhoods in Sri Lanka. In this study, the attempt was to identify the extent to which environmental features and social variables influence sense of safety in people when 
using public spaces and walking along neighborhood streets in Kotahena, Colombo, Sri Lanka. Past research has informed us that fear of crime has a connection to actual crime locations. This study attempts to find out whether there is a direct relationship between fear of crime locations identified by the residents to the actual crime locations.

\section{Sense of Safety and Fear of crime}

Much of the literature on feelings of insecurity or sense of safety comes from literature on fear of crime. Fear of crime is an emotion that can be associated with the potential for a crime to take place and refers specifically to crime related situations. In this study, we refer to sense of safety in relation to personal security. People can experience feelings of insecurity for many reasons; unsafe from traffic, slipping, and other causes. But in this study, feelings of fear refer to being unsafe from criminal victimization. Feelings of safety refer to being free from fear of criminal victimization. In these terms, for the purpose of this study, the working definition of sense of insecurity or fear of crime is effectively treated as the fear of becoming a victim which is associated with a specific context; this context refers to individuals walking in the City Centre at night. We seek to understand "sense of safety as an emotional response of dread or anxiety to crime or symbols that a person associates with crime" (Ferraro, 1995, p. 4). Adopting the scale used by Ferraro (1995), this study covers crime against a person: The aspects such as being attacked with or without weapons or being sexually assaulted and the acts such as being robbed or mugged on the street, having property (money or other valuables) stolen on the streets. We refer 'fear' or 'unsafe' as unsafe from criminal victimization. Feelings of safety refer to being free from criminal victimization.

This study primarily focuses on fear generating cues in selected streets of the multi ethnic and mixed residential neighborhood of Kotahena, Sri Lanka. Feelings of insecurity in streets or public spaces can be understood as being afraid, anxious, or concerned about personal security or predatory attack in public areas in relation to immediate environmental cues. To add further to this point, the current study focuses on the impact of physical features on people's perceived fear in the immediate environment (factors immediately surrounding a location) (Foster, Billie Giles-Corti, \& Knuiman, 2010; Nasar \& Jones, 1997).

\section{Environmental cues and sense of safety}

Feelings of safety or insecurity are associated with a range of factors. Literature informs that environmental features, lighting, and familiarity with spaces, presence of people, age, gender and ethnicity influence sense of safety. There has been a considerable amount of research on environmental clues as an explanatory factor in fear of crime. The relationship between environmental clues and fear of crime has been studied in environmental criminology, city planning, urban design and architecture. Goffman (1971) observed that individuals constantly scan the surrounding environment and react to dangerous situations. Building on Goffman ideas, some researchers have shown that certain signs or clues of the environment evoke fear (Warr, 1990;). Warr (1990) has shown that familiar environmental settings improve feelings of safety while new and unfamiliar environments may generate feelings of fear. In this case, familiarity of the settings acts as sign that improves spatial confidence. In this line of thought, Broken Windows Theory explains fear of crime in relation to macro environmental features (Wilson \& Kelling, 1982). Broken window theory expresses that if a building has a broken window and is left unrepaired, the other windows will be broken as people think that no one cares. This theory informs that disorderly or badly maintained physical settings may create feelings of fear among residents.

These ideas were further extended in Appleton's Prospect and Refuge Theory. According to 
Appleton (1975) people prefer both prospect (open view) and refuge (protection). Prospects can be open or closed and allow or prohibit opportunities for vision. Refuge can simply mean protection (shelter) or concealment (a place to hide).Places that offer both prospect and protection. Appleton believed that environments that afford more prospect (open view) and refuge (protection not for offenders) form an advantage to humans. Places that offer open views and protection help individuals and groups to observe potential threats or hazards (offenders), to defend from potential dangers, as well as to find a protective space to keep oneself from being harmed. According to this theory, people do not have to experience an area to determine its suitability or safety. They could scan their surroundings and assume the amount of prospect and refuge afforded to decide whether it forms a safe street or a neighborhood. Appleton's ideas influenced many researchers who attempted to explore the relationship between individual environmental preferences and micro level features in the built environment.

Building on the work of Appleton, Fisher and Nasar (1992) developed a safety model to explain the effect of specific features in the built environment and the feeling of safety by researching campus students at Ohio University in the United States. They used prospect for the victim and refuge for the offender as a framework for understanding how different exterior design features affect perception of safety. Using Appleton's concepts, Fisher and Nasar (1992) developed a general typology for evaluating individuals' perception based on the amount of prospect and refuge afforded within the surrounding environment. They argued that areas characterized by large amounts of refuge and minimal prospect would evoke the highest degree of fear amongst individuals. These areas are known as 'blind spots'. A considerable amount of refuge means greater possibilities of hiding places for potential offenders. Nasar and Fisher's model predicts that the highest degree of safety would be displayed in areas identified by minimal refuge for potential offenders and high prospect for victim. They argue that, if the surrounding area affords the victim a high degree of visibility / permeability and minimal hiding places for offenders, then the victim could evaluate the area and avoid the attack or opportunistic crime.

\section{Social cues and sense of safety}

Apart from the above research studies, scholars have introduced a variety of planning and design approaches and strategies to enhance sense of safety of people. Jacobs (1961) argued that urban spaces, such as streets and city squares should be designed with broader aspects of urban form, mixed land uses; and there must be 'eyes on the street', those belonging to 'natural proprietors' of the street. This implies that shoppers, residents and pedestrians need to be able to watch street activity. Jacobs' ideas assert that people feel confident to be and move within urban areas when they are not isolated from contact with the larger urban realm. When people are seen by others, it allows casual surveillance and those bystanders may provide assistance in unsafe situations. The ideas of Jacobs were further extended by Newman (1972). Newman in his 'Defensible Space approach,' emphasized that architectural design (buildings heights, windows, staircases) and urban design features (streets, open spaces) could improve community cohesiveness and can create a 'defensible space' against criminal activity. The essence of defensible space program is to restructure the physical layout of communities to allow residents to control areas around their homes. This includes the streets and the grounds outside their buildings, lobbies and corridors within them. Newman believed that these environmental designs not only protected them from criminal activity but enabled people to realize their commonly held values and life styles.

Apart from above ideas, Crime Prevention through Environmental Design (CPTED) and Situational Prevention of Crime (SCP) approaches have been widely used by planners, 
architects and urban designers to prevent crime and improve the sense of safety of people. CPTED approach proposes to utilize design features to increase the visibility of a property or building through quality of lighting, proper placement and design of windows, lighting and landscaping. It also considers a range of access natural and mechanical access control-locks, bars, and alarms. A gate and wall around a housing scheme are examples of access control measures that may protect residents from wandering off and inhibit entry of potential offenders. Furthermore, the CPTED approach proposes territorial reinforcement (e.g., demarcation of private and public spaces) and maintenance of buildings to make people safe (Crowe, 2000; Newman, 1972). The SCP approach introduces managerial and environmental change to reduce opportunistic crimes from occurring. It focuses on environmental settings for crime, rather than on those committing criminal acts (Crowe, 2000). This approach proposes measures such as installment of locks, vandal-resistant designs, neighborhood watch initiatives, intruder alarms, close-circuit television cameras (CCTV) cameras and defensible space recommendations proposed by Newman (1972).

\section{General sense of safety}

The perception of safety varies with age, sex, and culture. Women and older persons have a different sense of safety as compared to others (Mehta, 2013). Many research findings confirm that females feel significantly less safe than males when they walk at night in public spaces (Fisher \& Nasar, 1992; Kelly, 1986; Yavuz \& Welch, 2010). This may result in females behaving differently in spaces at different times of the day.

A considerable amount of research has examined ethnicity as an explanatory factor in fear of crime. Some research has revealed that non-white people felt less safer than white people (Fisher \& Sloan, 1995; Lagrange et al., 1992). Similarly, when many races/ethnicities were examined in the United States, Whites were more likely to feel safer than Blacks and Hispanics (Kareem \& Gabbidon, 2010). One main explanation provided to understand this correlation connects to impoverished physical condition of the living environment. Studies have found that a disproportionate number of minorities live in impoverished housing areas (Davis, 2006). The conditions in such physical environments (e.g., graffiti, incivilities, dilapidated buildings, etc.) tend to signify a risk of victimisation among inhabitants.

The above theoretical discussions inform that sense of safety can be studied by many approaches. Past research has shown that fear of crime has been extensively studied in the Western context. In planning and design projects, researches tended to focus their attention to explore the relationship between feelings of safety or fear and physical features and design elements in the urban settings. We know little about how the combination of physical features and social variables influence sense of safety. At the same time we know little about fear generating factors in urban neighborhoods in Sri Lanka. Therefore, in this study, we attempted to explore how environmental and social variables such as gender and ethnicity contribute to the sense of safety of residents in a neighborhood area in Kotahena, Sri Lanka. We believe that a study of this nature will help planners and designers to understand factors that contribute to feelings of fear or safety and help to design comfortable and flourishing urban settings for people. 


\section{Method of study -}

The main objective of the research was to comprehend the social and environmental characteristics which negatively affect the sense of safety in urban neighborhoods. For that purpose, in the first stage of the study, residents were asked to indicate locations that they felt fear and safe in the case study area. The locations identified by Individuals were clustered as safe and unsafe locations and six sites were selected for further analysis. In the next stage, the residents were asked through a questionnaire to express their level of fear (as safe, unsafe, not relevant) by considering the contribution of each environmental and social factor identified on theoretical framework.

The selected participants (20 to 35 samples for each spot) were all residents in Kotahena (primary source). Kotahena Police crime maps were taken for further reference and fear layout maps of residents were overlapped with police crime layout maps of the area. This was done to investigate the relationship between actual crime hot spots and locations where feelings of fear were sensed by the residents.

\section{Case study: Kotahena}

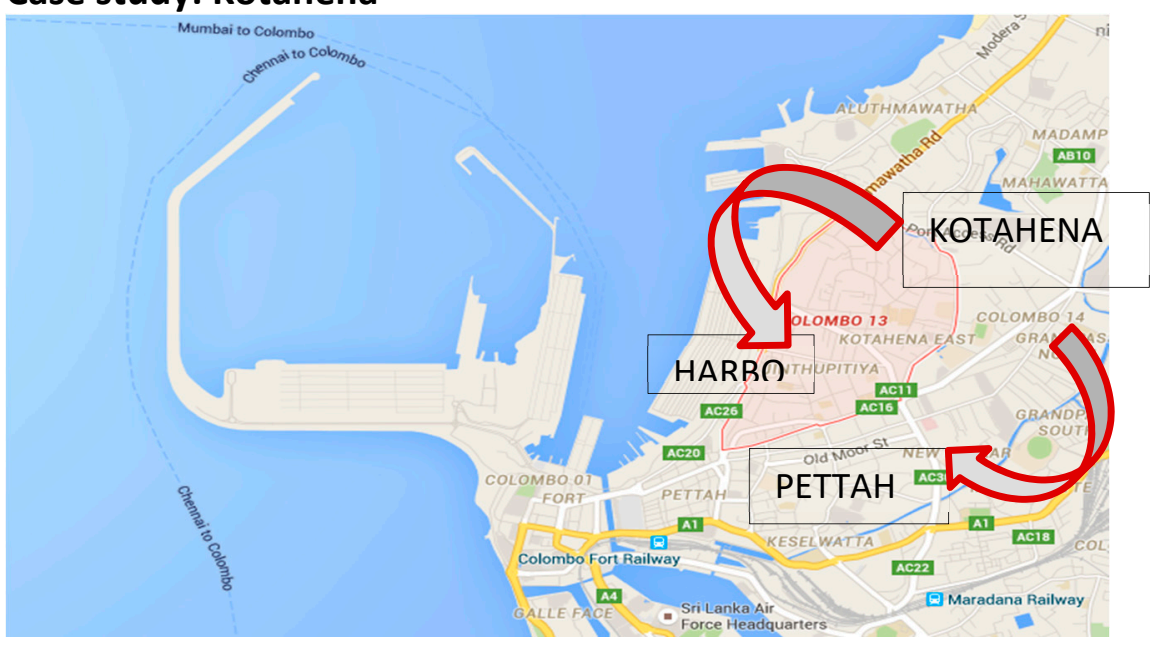

Figure 1: KOTAHENA: main labor supplying source to Pettah market and harbor

Source: Google maps

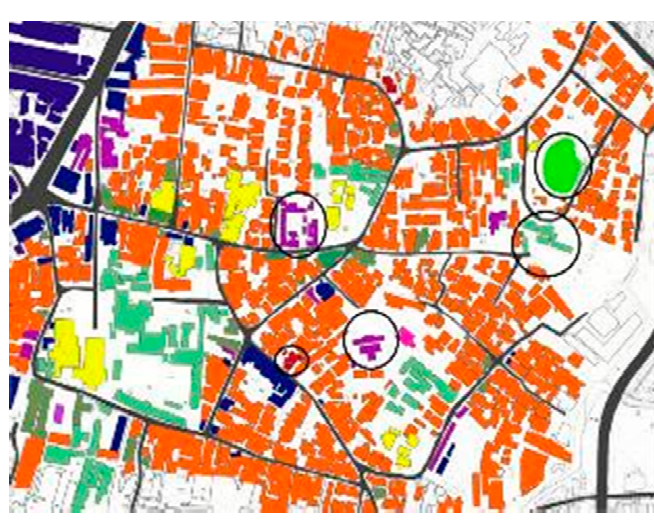

Figure 2: Building used map; Kotahena Source: author

Kotahena is a mixed residential urban sector in Colombo, Sri Lanka. The physical definition of Kotahena consists of a fine grained built fabric, with lower middle income to middle income housing. There is a rich mix of housing types ranging from single and double story houses to a series of vertically developed compact buildings. Houses that open on to the street represent the way of life and the social and economic background of the occupants. While there are a few prominent buildings that serve as landmarks in Kotahena, the general built fabric is chaotic and of no specific architectural character. Kotahena has a mixed land use pattern ranging from housing, to commercial activities, a few prominent schools, religious institutions and a prominent sports venue. It is also one of the main labor supplying sources for the Pettah market and Colombo 
harbor. It has a strong multi-ethnic, multi-cultural community where a majority was represented by the Tamil population in the census and statistics of 2013. Some parts of Kotahena are occupied by underserved settlements and the .Imbalanced social and economic profile and the chaotic built environment have aided many socio-cultural disorders within the area.

\section{Overlaying the Fear Spots in Kotahena with Police Crime Spots}

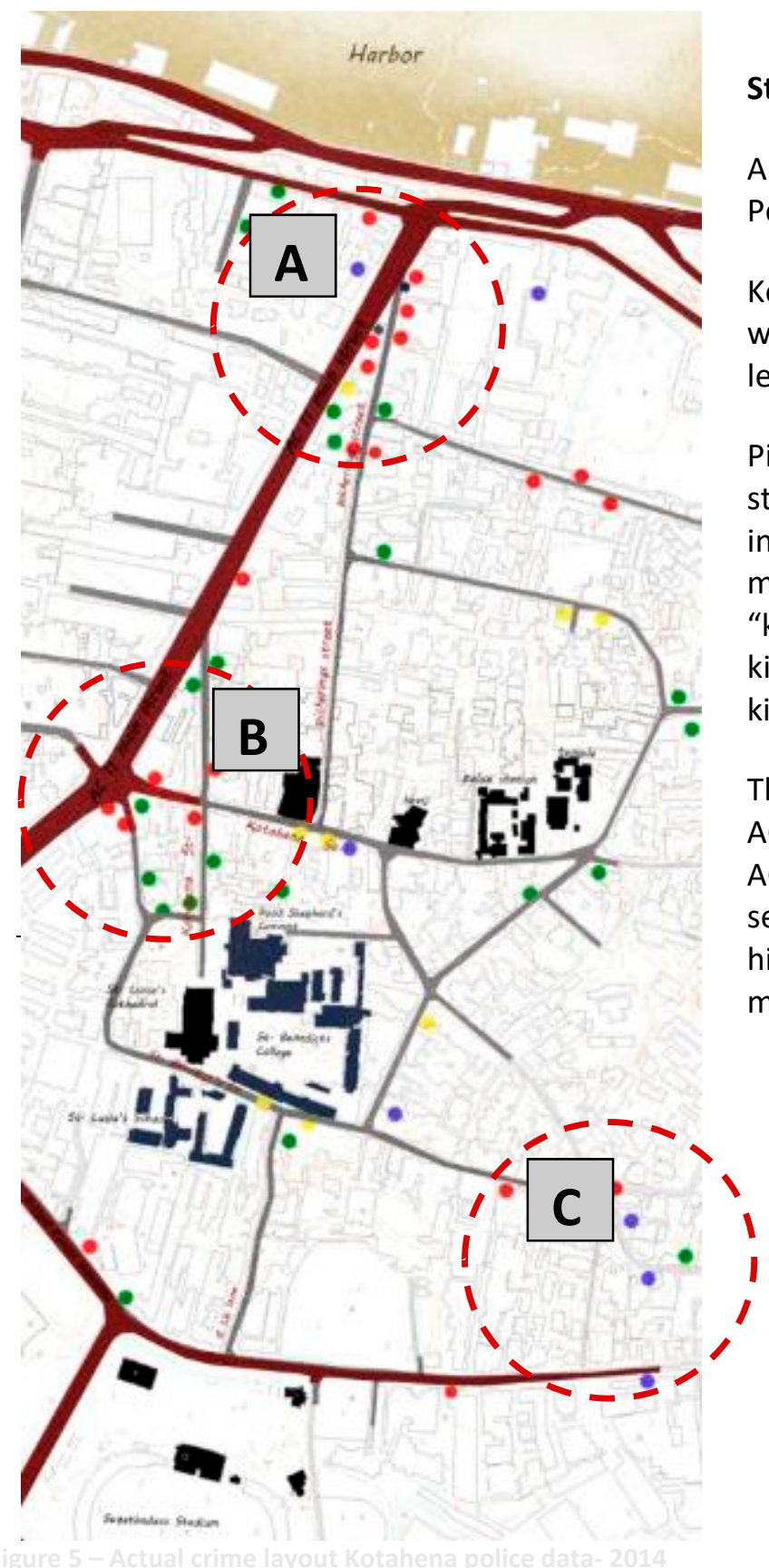

Figure 3: Police crime layout, Kotahena Source: Crime Division, Police Station, Kotahena

\section{Step I - mapping police crime spots}

All research data were taken from the Kotahena Police Crime maps of 2014.

Kotahena Street as a commercial street bustling with activity most part of the day showed a low level of crime activities.

Pickerings road though primarily a residential street, showed the highest rate of crime including inflicting injuries and attempted murder. (Though it has been mentioned as "killing" in the police crime layout legend; no killings/murder has been reported. Therefore killing refers to attempted murder).

The junctions where Kotahena street meets the AC 11 main road (B) and Pickerings road meets AC11 (A) are the busiest junctions within the selected area of study. These junctions have a high crime density where theft and attempted murder is reported as high. 


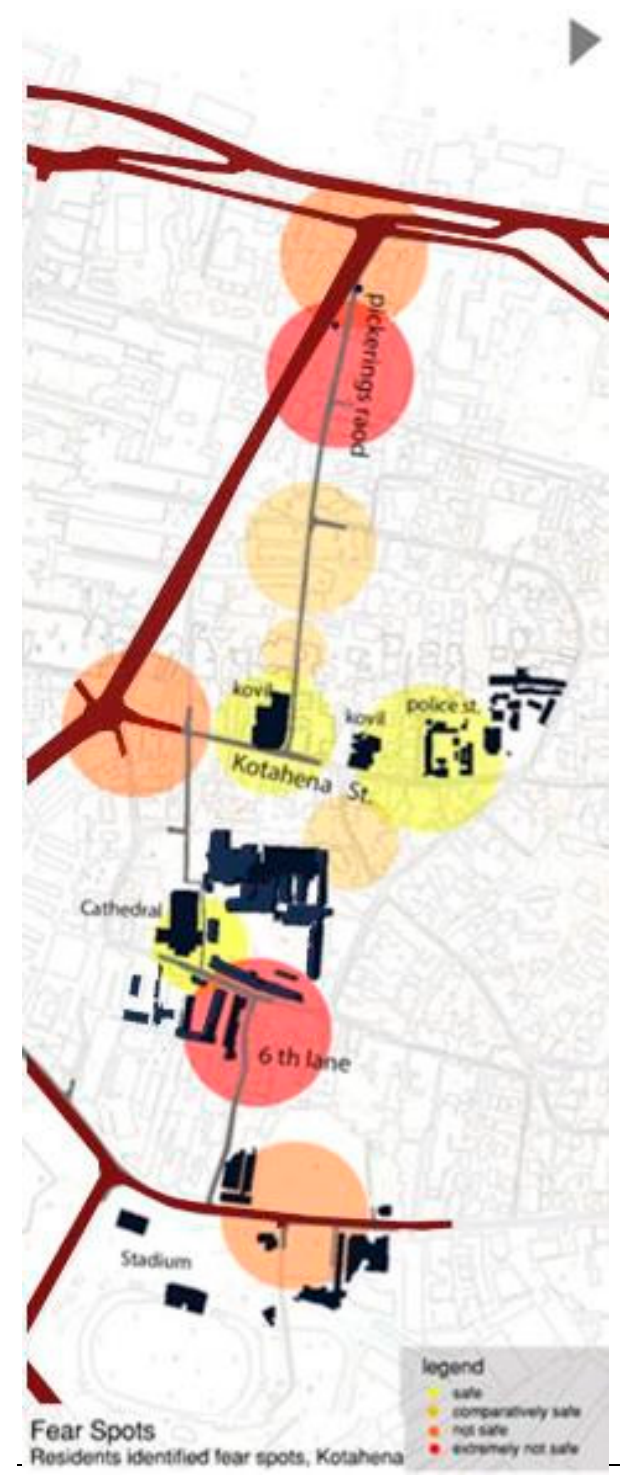

Figure 4: Residents identified fear of crime spots, Kotahena

Source: author

\section{Step II - mapping residents' fear spots}

Data was gathered by conducting a survey on a sample of 76 participants; which included 42 females and 34 males. All the participants were residents of Kotahena who had a high degree of awareness of the area.

Participants were asked to mark areas in their neighborhood, that they felt a varying sense on fear of crime, under four categories (safe, comparatively safe, unsafe, and extremely unsafe).

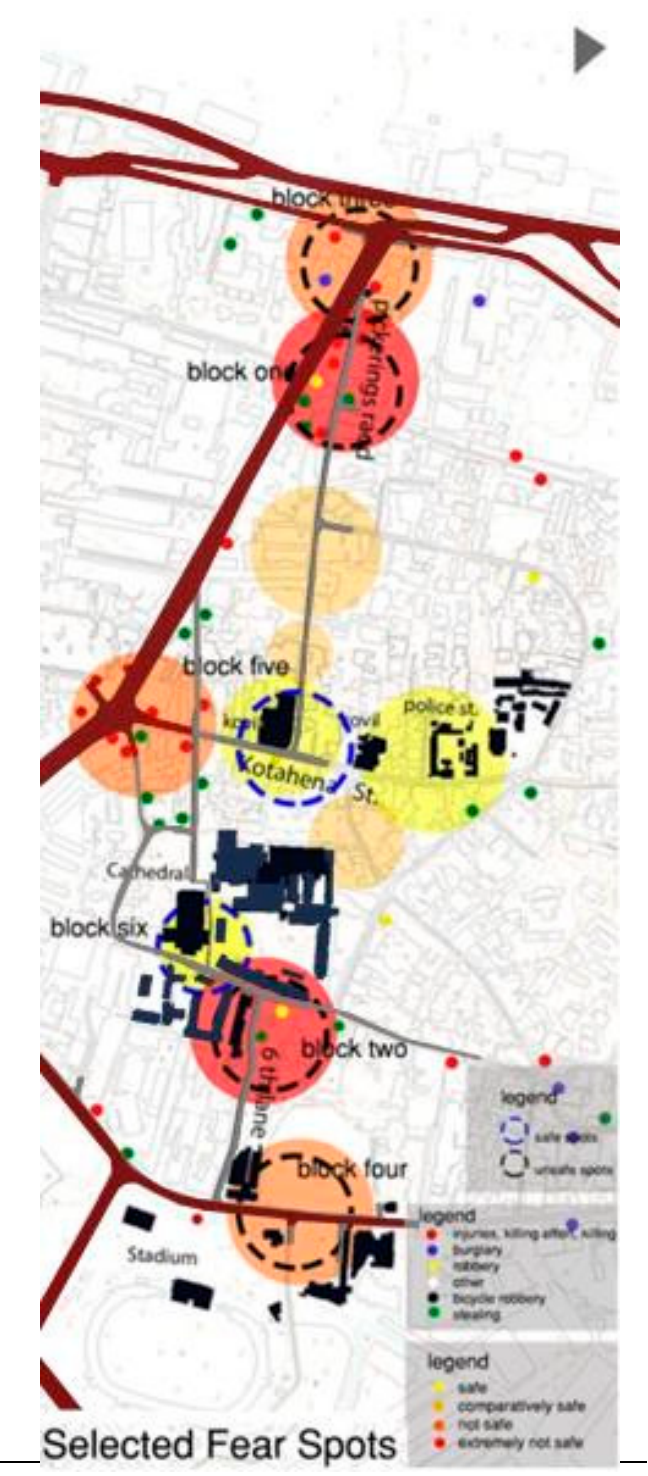

Figure 5: Overlaying police crime map with residents' fear of crime spots

Source: author

Step III - overlaying the police crime map with residents' fear of crime spots

Layout of "fear spots" identified by the residents perception of fear of crime, and hot spots identified from the Police Crime Data, 2014 were overlapped to comprehend the relationship between the actual crime locations and "fear of crime" locations.

Areas $1,2,3$ and 4 were identified as fear evoking unsafe places and Areas 5 and 6 were identified as safe secure places by residents who participated in the study.

Though there isn't any reported history of crime, Area 04 was mentioned as an unsafe place by residents. Area 05 has a crime history of robbery and yet was perceived as a safe place by the residents. 


\section{AREA 01 : ( eyes upon the street has evoked a sense of fear, disordered chaotic built environment has become a neutral factor)}

Out of the 35 people who participated in the survey, 16 were males, and 19 were females.

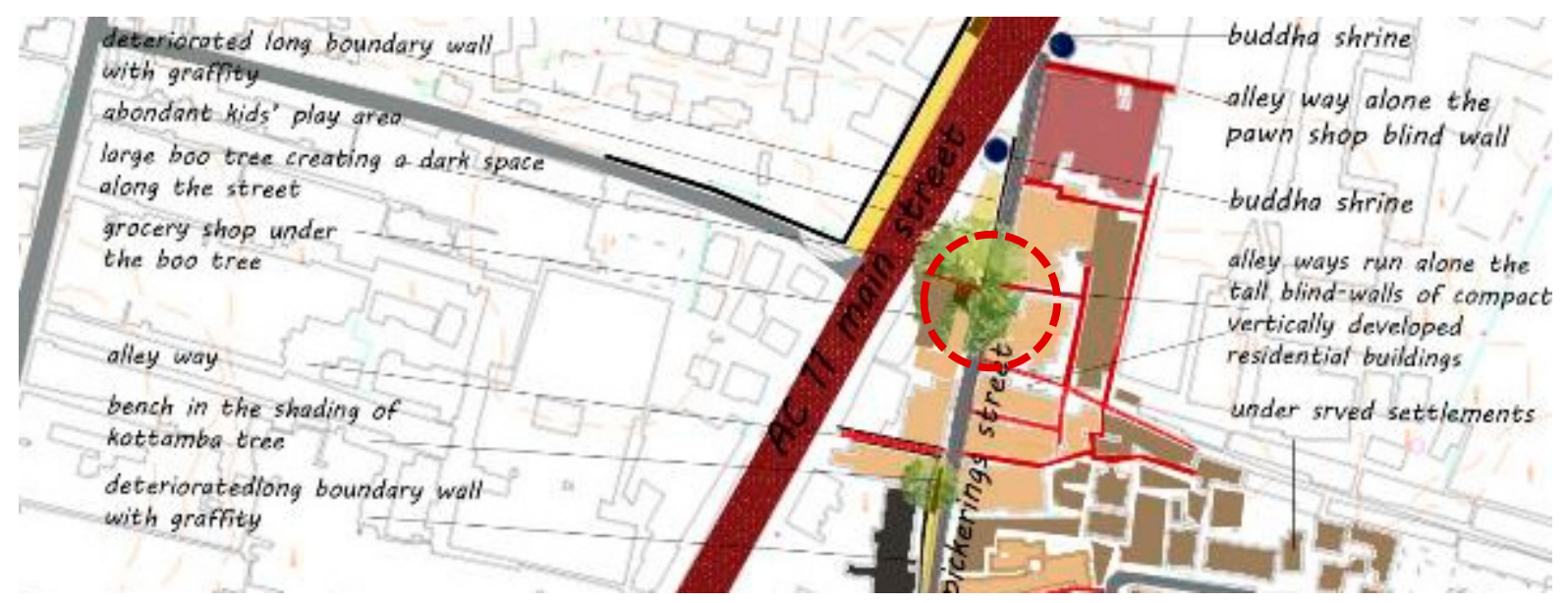

Figure 6 : Area 1

Source : author

According to Police crime data, Pickerings street has a high crime rate especially with regards to theft, injuries and attempted murder. This is also one of the most fear evoking places identified by residents. This area mainly consists of vertically developed compact low income settlements creating a series of alleys, dark corners for gathering and access.

'Eyes upon the street' is a common occurrence in Pickerings Street as there is a constant presence of people on the street and neighborhood buildings. Since the building line is almost on the street, space for a verandah or a courtyard doesn't exist in many cases. As a result the street becomes their living room for conversations, arguments and celebrations. The vertically developed compact residences have openings on to the street. Residents communicate with their neighbors on the opposite side of the street by leaning out from the' balconies on the upper floor. This physical definition of buildings and behavior of residents have improved the spatial confidence that people have along the street.

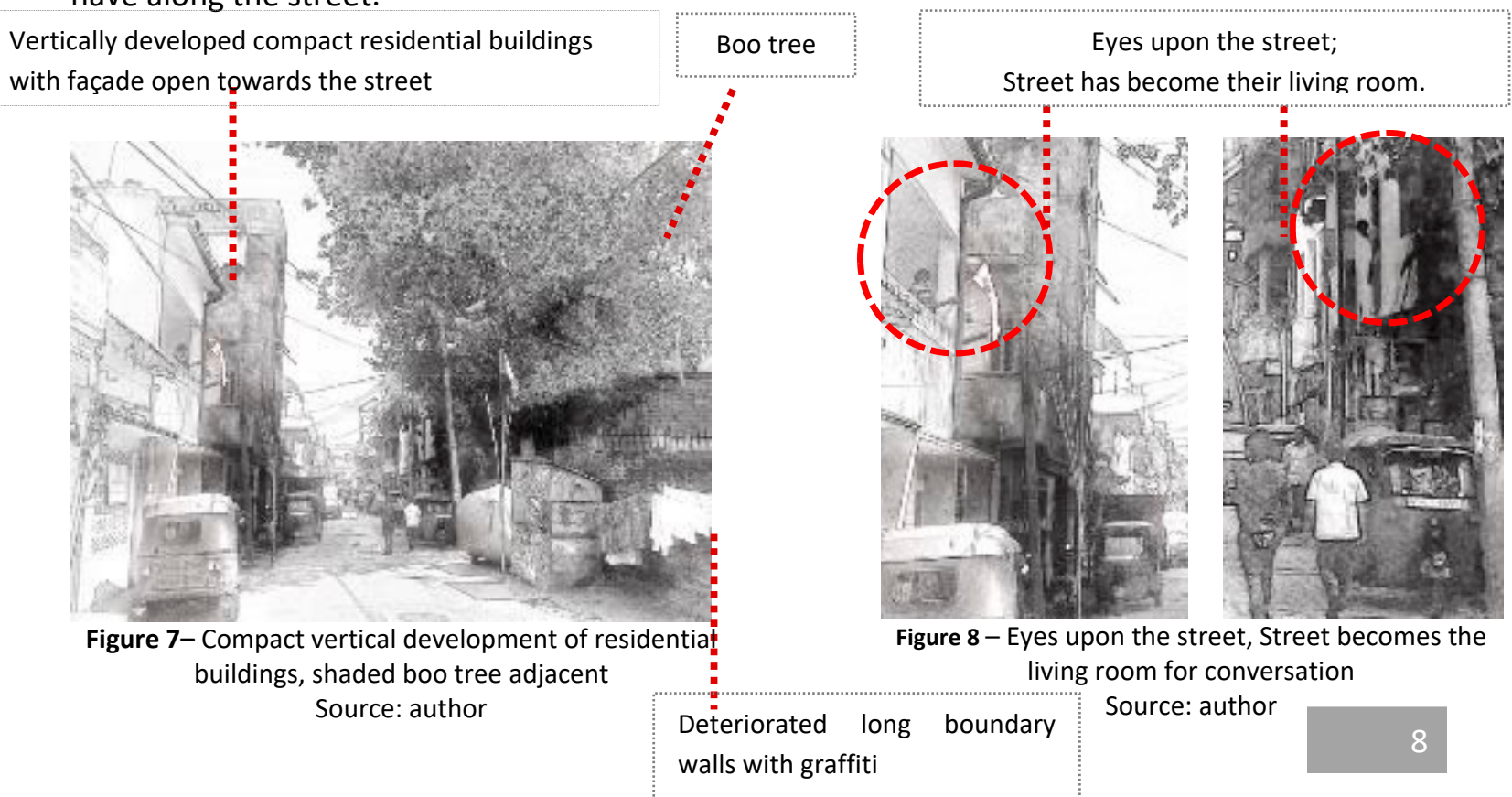


Yet, some parts of Pickerings Street was considered unsafe as many narrow and dark alleys run between blank side walls of vertically developed compact low income settlement to the underserved settlements beyond. Signs of vandalism, graffiti and junk are visible along the long boundary walls \& road, increasing the level of anxiety expressed along the alleyways. These places have often become gathering spots for engaging in many socially unacceptable activities related to drugs and gambling.

Moreover, the dark, shaded area created by the thick tree canopy on the main street has become a main fear spot for the residents (especially for females). It was mentioned that this shaded dark blind spot was often frequented and dominated by groups of young males who were engaged in activities related to drugs and gambling. The bench below the canopy of the tree and the little grocery shop are nuclei where young groups of males gathered. Some of these young crowds are trishaw drivers and others who do not have a permanent occupation and loiter around.

\section{AREA 02 : (blocked vistas - street bends between long boundary walls and blank walls)}

30 people including 10 males and 20 females participated in the survey.

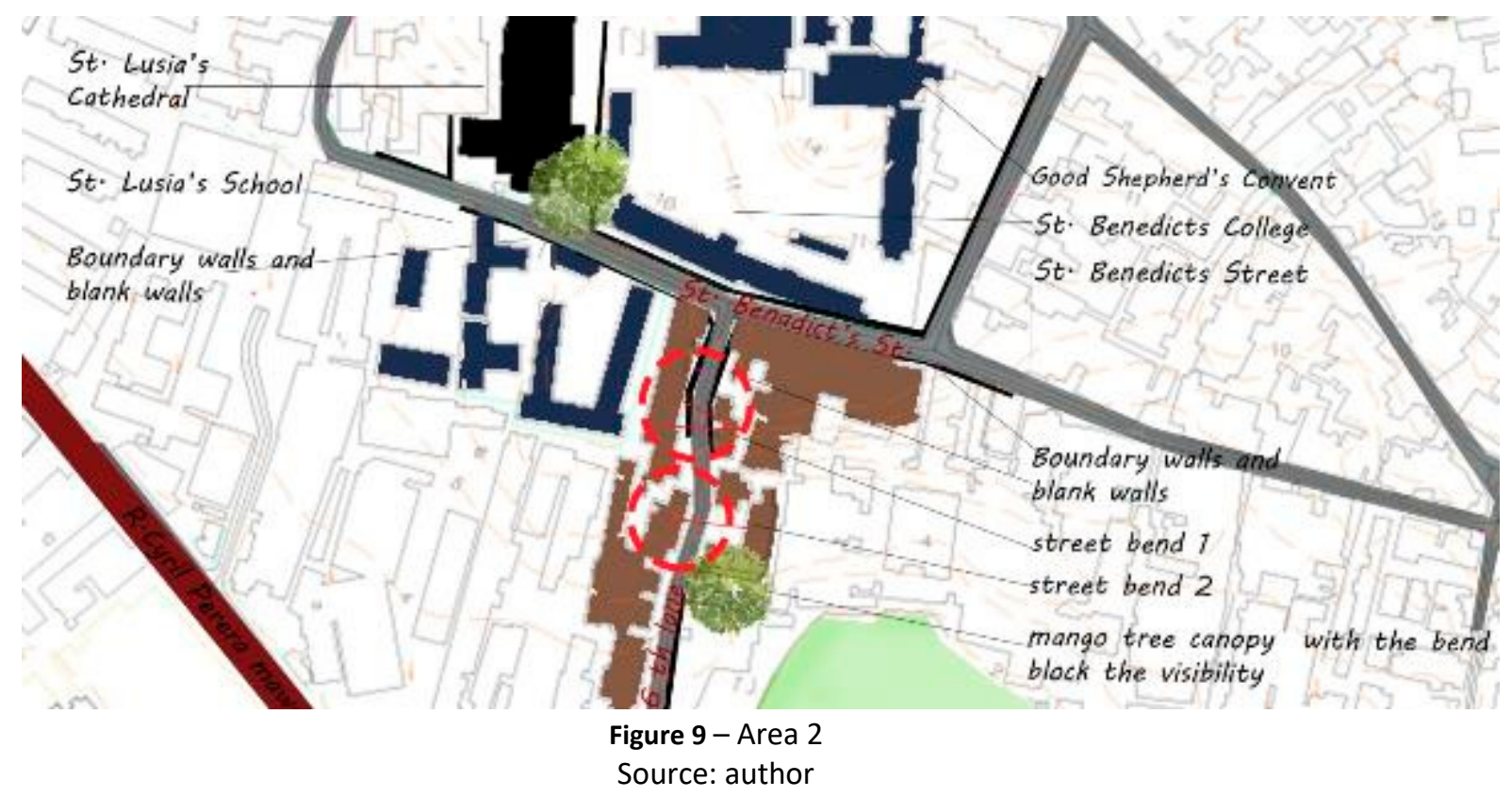

According to police crime data, Area 02 has a prominent crime history related to robbery. The place also has been identified as one of the most dangerous places by the residents.

The long, impermeable solid boundary wall of the school and the blind walls of neighborhood residential buildings with graffiti create an unwelcoming edge to the street from the school side. Three wheelers parked along the lonely Streets (St.Benedicts' st. and $6^{\text {th }}$ lane) are the only entities that give a hint of presence of people. Yet, their presence has not become a social cue that encourages a sense of safety.

Many female participants identified long blank walls as trapping the space creating a lonely street that affects their personal security as unsafe from criminal victimization. The presence of three wheeler drivers enhanced the sense of insecurity felt as there was fear of the unknown in the subconscious mind, as they felt that there is a possibility of being mugged or in extreme cases even fear of abduction. In their expression and interpretation, there appears to be a higher possibility of refuge for an offender although the street has greater undisturbed visibility which offers prospect 
for the pedestrian. Here, the continuous walls that do not offer permeability to escape enhance their sense of fear.

Moreover, the $6^{\text {th }}$ lane has two bends blocking the view beyond. Not knowing what could take place beyond the bend has given residents a sense of fear of being victimized, due to fewer opportunities to find a way of escape. The street bends block the view of the destination while the high blind walls and presence of three wheelers evoke anxiety of becoming a victim.

\section{AREA 03 : (presence of strangers is not a fear factor)}

25 people including 9 males and 13 females participated in the survey.

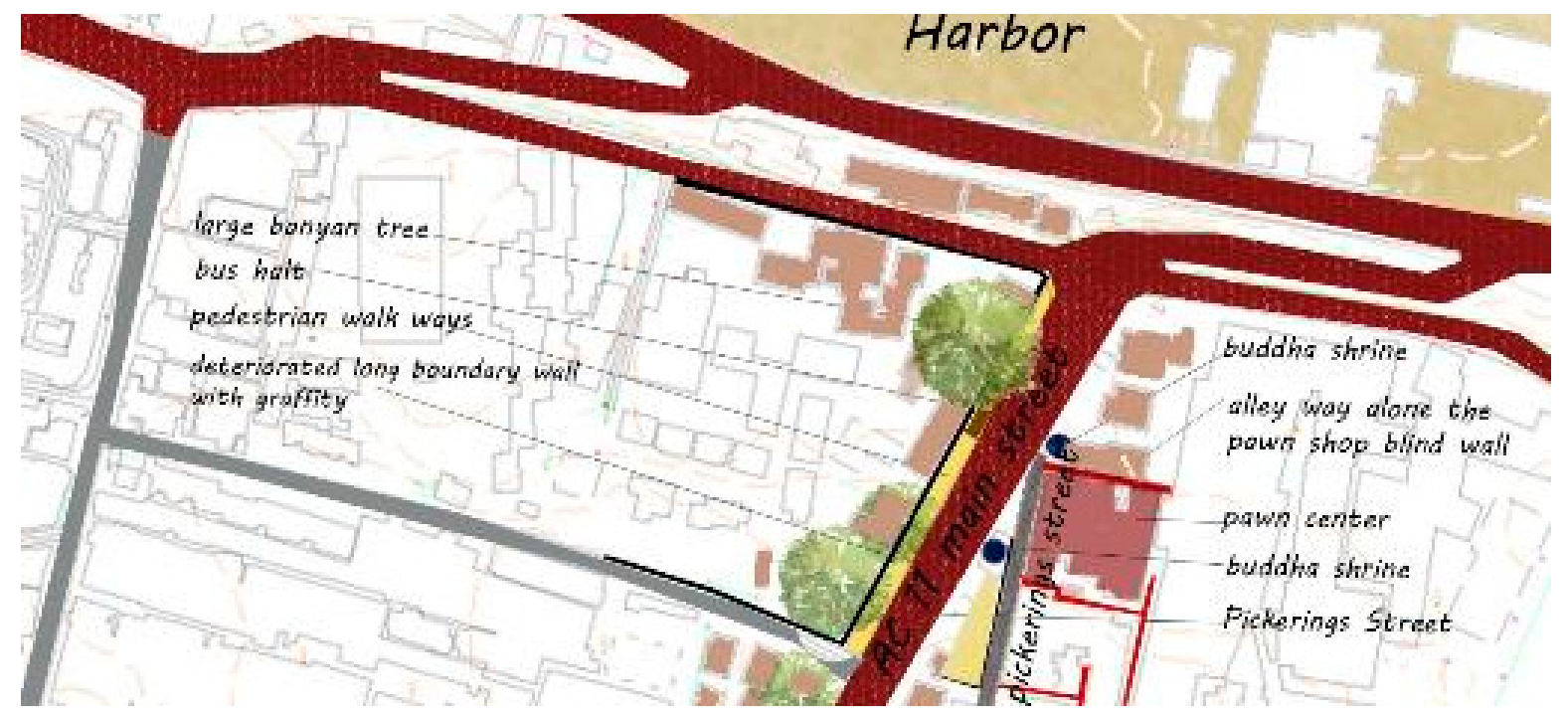

Figure 10: Area 3

Source: author

Area 03 was identified by the residents as a place that evokes fear. According to police crime data, the place has a high crime rate related to burglary, injuries and attempted murder.

Area 03 is close to the main junction where Pickerings street meets the AC 11 main road. One end of Pickerings street consists of a higher number of active buildings such as a pawn center and a Buddha statue that people come to worship. The area adjacent to the pawn center is frequented by young male groups during most parts of the day. The opposite side of the AC 11 main street has a sidewalk and a bus stop. AC 11 main street is well lit during night time. There is sufficient daylight with a clear view of the harbor ahead. A large banyan tree with a thick tree while providing shade has created a dark atmosphere beneath, forming a blind spot. This area was identified as fear evoking spots within the vicinity.

Although Pickerings Street opens out to a main road ( $A C$ 11), the presence of people along the street is very low. This area is mainly a transitional pass-through space which is always busy with vehicles that proceed to the harbor and to Pettah. The area with the shaded banyan tree and long boundary wall was mentioned as an unsafe place, where vandalism represented by graffiti is visible on the boundary wall. Since strangers are common on the main road, Presence of strangers was accepted as a neutral social cue by most of the residents. 


\section{AREA 4 : (low density of people compared to the large expanse of open green spaces)} 25 people including 18 males and 7 females participated in the survey.

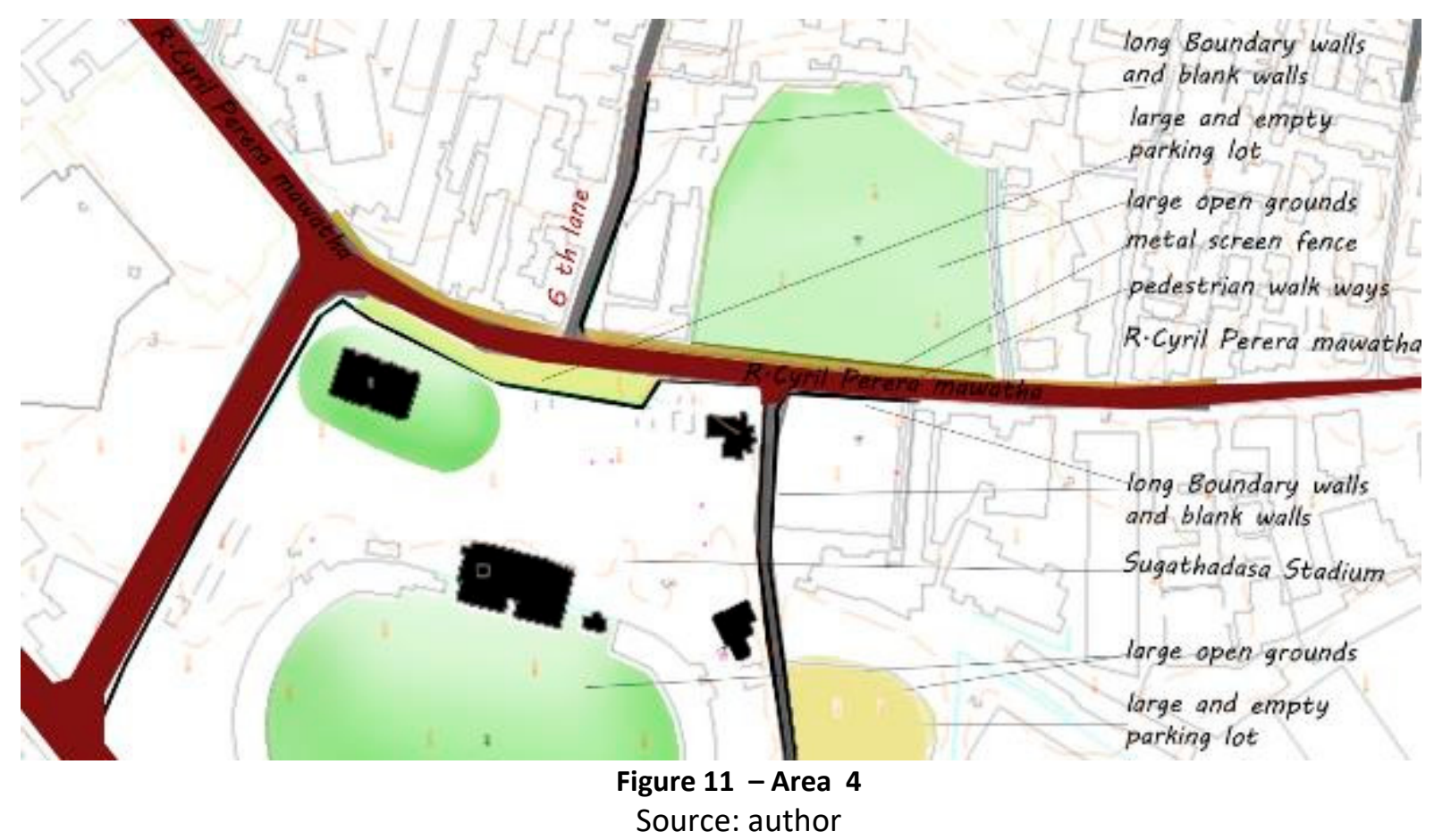

Area 04 is one of the most important segments identified in the study. Though the area was identified as an unsafe place by residents, no crimes were reported in the police crime reports.
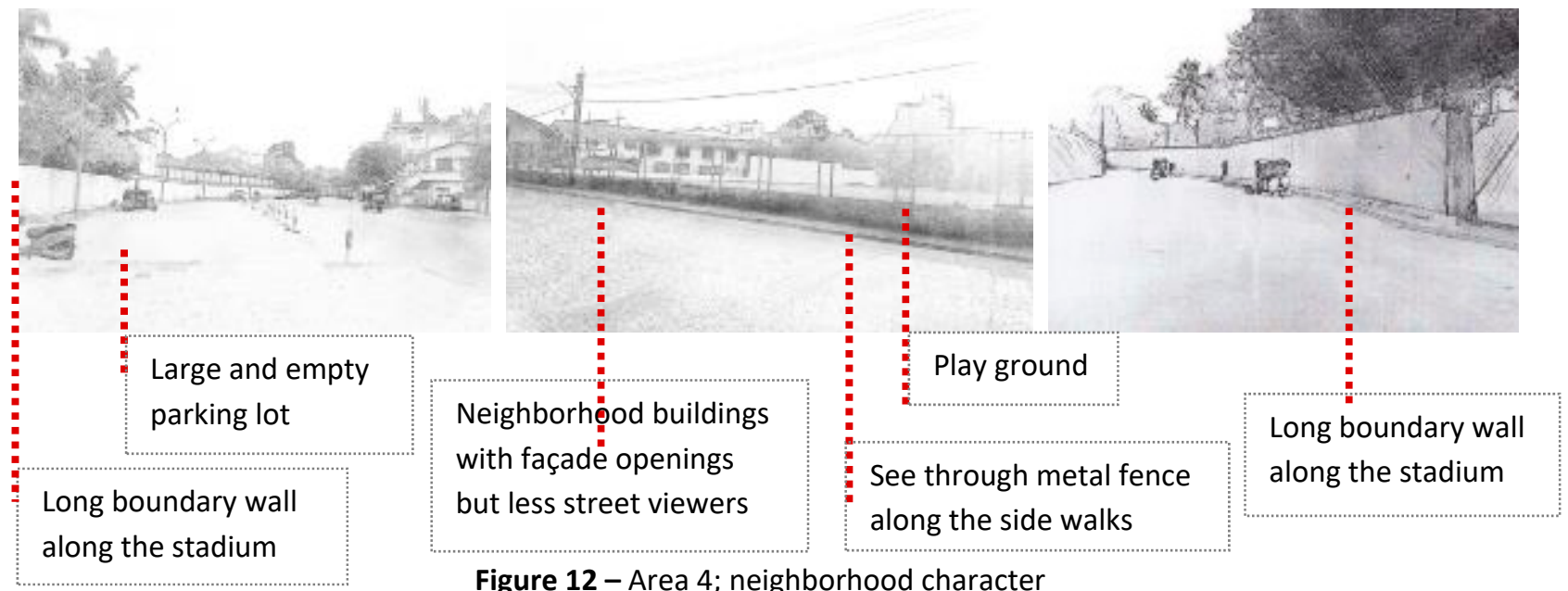

Figure 12 - Area 4; neighborhood character Source: author

The wide parking lot of Sugathadasa stadium, and the large play ground on the opposite side of K. Cyril C. Perera Street enables wide open views and vistas along the sidewalks. The street is well lit. Yet as mentioned by residents, the presence of people is extremely less during most part of the day. The stadium and playground do not function on a regular basis. Moreover, both spaces are blocked off physically by a fence. The empty large parking lot often occupied by three wheelers has created an uncomfortable environment to the residents. Although the buildings nearby have openings, there 
are no visible occupants to watch the street and provide casual surveillance. The boundary walls that continue for a considerable distance along the street have created a high level of insecurity enhancing the fear of criminal victimization.

\section{AREA 5 : (crowd themselves provide refuge for offenders to hide and escape $)$}

30 people including 18 males and 12 females participated in the survey.

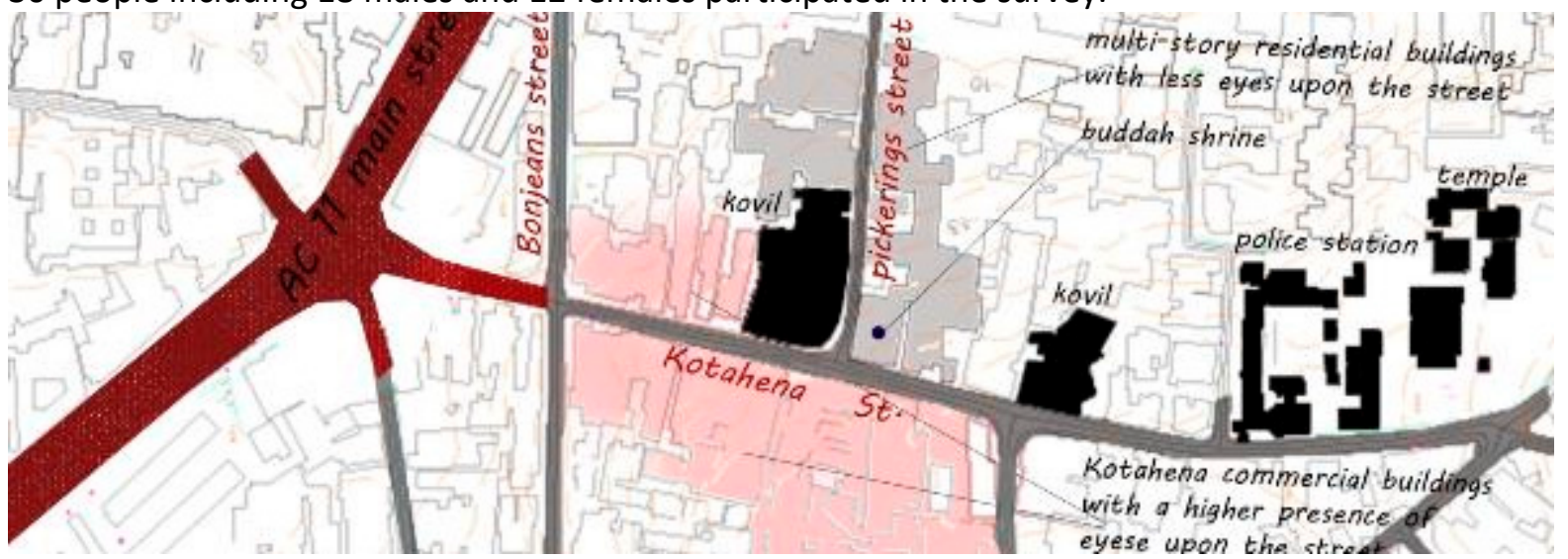

Figure 13 - Area 5

Source: author

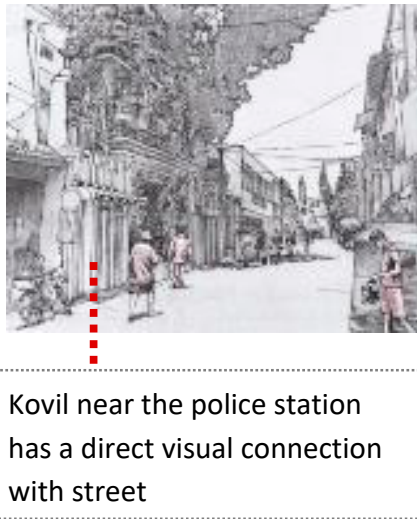

Vertically developed compact commercial buildings with façades opening on to the busy $\&$ crowded Kotahena Street
Vertically built residential blocks with façade openings covered with steel grill works
Figure 14: view of the busy Kotahena Street Source: author
Figure 15: view of the Pickerings Street Source: author

This area is the other most important hot spot identified in the study, which was considered a safe area by residents, but with a history of crime related to robbery as per police reports.

Area 05 is located on the junction where Pickerings road meets Kotahena Street. Two important kovils which add a vibrant character to the context are located around the junction. The Kotahena Street consists of many commercial buildings, while Pickerings road has a series of multistory residential blocks. Both commercial and housing blocks contain a higher number of openings on to the street. Although the tall residential buildings on Pickerings road have wide openings at ground level, they do not provide any visual protection to pedestrians as the openings are covered with steel grills and the occupants in most of the houses are not present during the day to watch the street. 
Kotahena Street (being the main commercial street) is used by vendors, customers, residents and pedestrians constantly watching the street. Though there are no physical blind spots for offenders, the dense moving crowds on the street itself enable hiding places /refuge for offenders. The density of people constantly on the move reduces visibility and prospect for the pedestrian.

\section{AREA 06- sound gives the sense of presence of people (auditory safety)}

28 people including 8 males and 20 females participated in the survey.

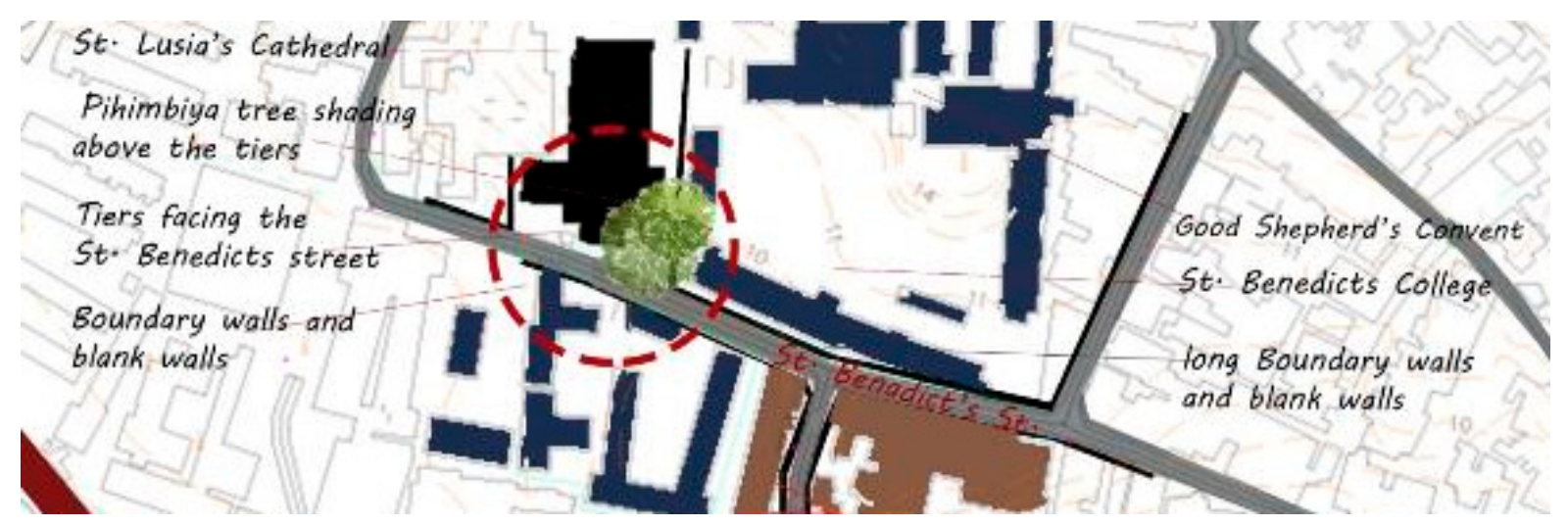

Figure 16 : Area 6

Source: author

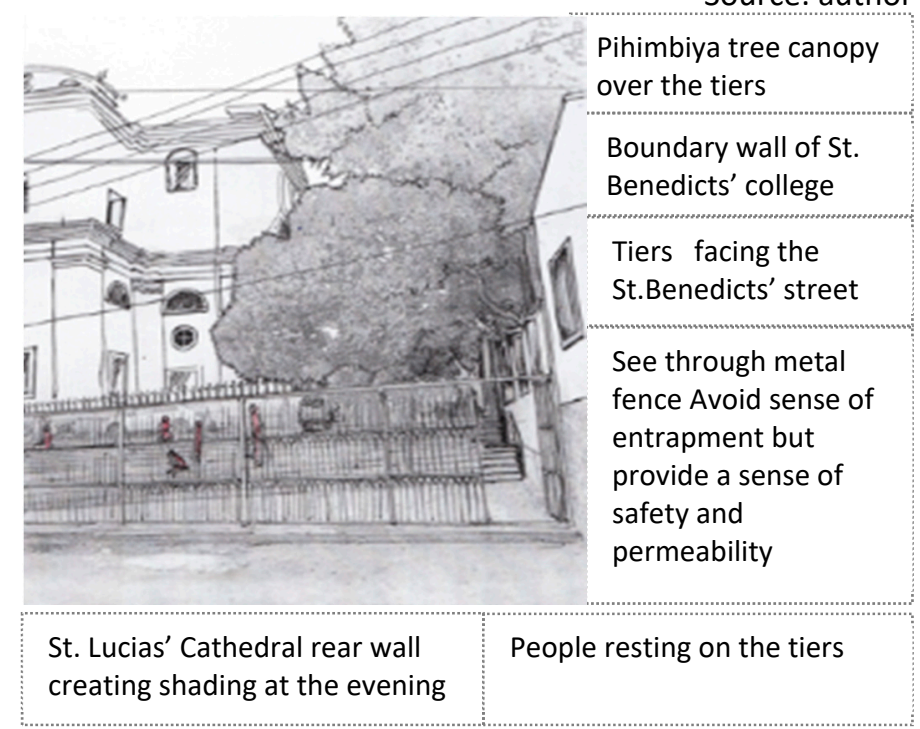

Figure 17: Public resting on tiers under the tree canopy Source: author

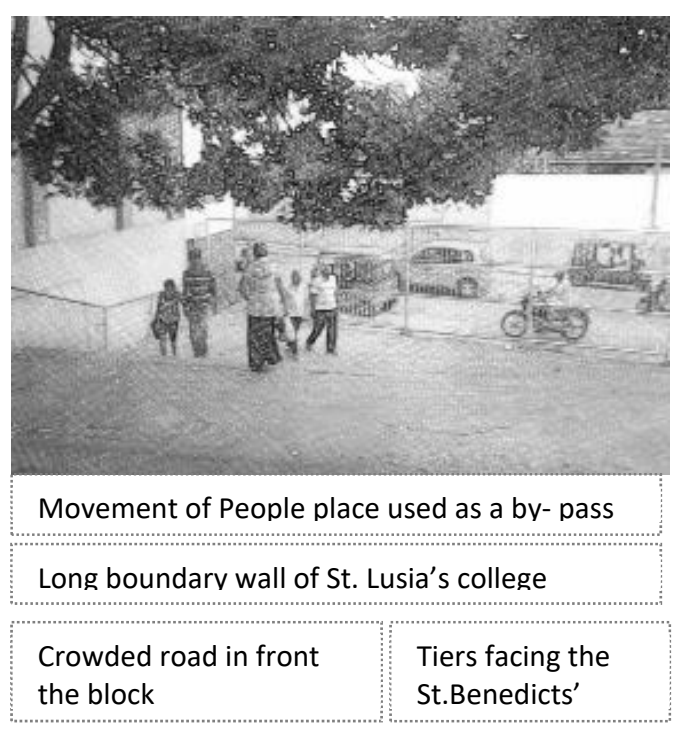

Figure 18: view of movement of neighbors through the area throughout the day Source: author

As per the residents' comments, this is the safest area within the context. Though Area 06 doesn't have a significant crime history, Area 02 located approximately $100 \mathrm{~m}$ away from this location has a long history of criminal activities and violence.

The particular street under consideration runs between St. Benedicts College rear side wall and front wall of St. Lucia's College. The high structure of St. Lucia's cathedral provides ample shade during the evening. Moreover, shade provided by the thick canopies of the two trees by the tiered steps enables a comfortable public place behind the cathedral.

According to residents, the most important feature here, are the "tiers". The seating facility, shade and greenery, with the presence of people have made this a safe place to be. Here "Presence of people" refers not only to the people who are visible, but also to the continuous sound of school 
children which provides comfort and a sense of safety. The land use and building use pattern with public and cultural buildings around has enabled a place that attracts people. Clear broad vistas and street light condition are also at a satisfactory level. Unlike Area 01, shade here has become a positive variable, which has enabled the place to function as a good public place. The sound of children has increased the degree of sense of safety by giving an audible sign of presence of people.

\section{Discussion and Specific findings to Kotahena}

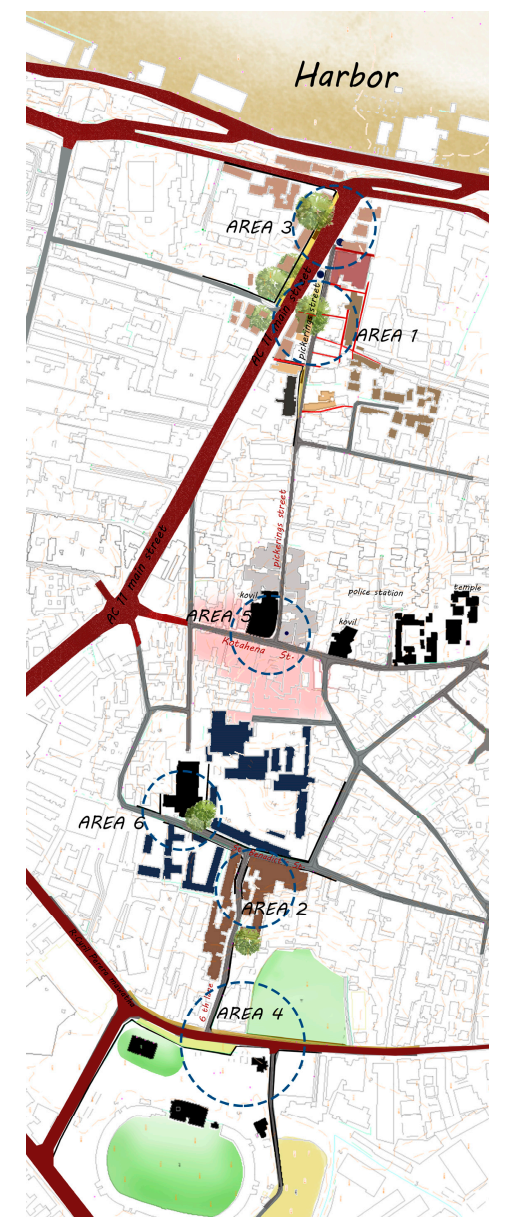

Figure 19 : case areas

Source: author

Areas $01,02,03$ and 04 have been identified by residents in Kotahena as unsafe spots that evoke fear of crime. Areas 01 and 02 are residential areas with chaotic, deteriorated, buildings with signs of vandalism on walls, facades \& roads. Although the vertically developed compact buildings have façades opening onto the street, 'Eyes upon the street' has become a fear evoking variable in Area 01 due to disreputable behavior of neighbors which has induced a sense of fear of crime. Area 03 is a main junction surrounded by commercial buildings. All three areas have clear broad vistas where the legibility of the blocks has been disturbed in some places by the thick tree canopies and street bends.

Although literature highlights that there is a relationship between actual crime locations with fear of crime spots, Area 04 without a single crime related activity was identified by respondents as an unsafe place that evokes fear of crime. It has clear broad vistas, good street light conditions, broad sidewalks for pedestrian, large parking lots and play grounds, yet, the prominent absence of social cues has triggered a sense of fear within the area. The large open grounds, parking lots with long boundary walls have become empty places where a lesser human presence is visible. The character of the area has possibility of becoming a crime breeding spot in the future.

Areas 05 and 06 were identified as safe locations even though Area 05 reported crimes related to robbery. Clear permeability through building facades towards the street, with a higher presence of people are cues that provide sense of safety in Area 05. The same characteristic of 'presence of people' has provided refuge and

escape to offenders.

Area 06 with shade and tiers providing seats has made it a good public place. The see-through gate has aided in providing a sense of safety through its visual permeability. The continuous movement of residents who use the place as a bypass has added a visible sense of 'presence of people'. The sounds of children in neighborhood schools have given an 'auditory safety' to the user.

Broken window theory discusses how disordered, chaotic built environments evoke fear. In Kotahena, however, the chaotic built environment is not a main fear-evoking factor. Familiarity with the poorly maintained, disorderly built environment has become a neutral factor, which does not evoke fear. Area 01 is the best example for this finding.

Jane Jacobs (1961) discusses the importance of natural proprietors in creating 'eyes upon the street' to preserve a sense of safety. However, in Area 01, most of the people present in the vicinity were groups of young males from the underserved settlements with a high drug related crime history. 
Therefore, 'eyes upon the street' in this instance was identified as fear generating variable in Pickerings street.

Environmental cues such as shaded places, spaces with clear broad vistas have been identified as cues that increase the level of sense of safety. Shade is an essential requirement in a tropical country such as ours to increase the usability of spaces while attracting more people to public places. Similarly, it is accepted that clear broad vistas provide more prospects for the general public against possibilities of victimization (Nasar, 1992). Yet in Kotahena, certain places with both these environmental cues have been considered as highly unsafe places. Shaded places have become attractive places of refuge for offenders.

Past research also states 'presence of people' as a safety factor (Nasar, 1997, Ratnayake, 2003). Yet findings related to Area 01 reveal that presence of people as natural proprieties is not always a safety factor. Area 05 shows how offenders are likely to use places with high density of people or 'presence of people' as a variable to hide and escape.

Females and elders often have similar fear levels (Mehta, 2013). Their physical and mental strength may influence this variation. Youth in Kotahena were found to be less affected by the neighborhood characteristics and usability of urban space, while elders were more aware of their neighborhood.

Factors such as ethnicity and familiarity with the place have shown similar influences on the fear of crime In Kotahena. Newcomers to the context (who are not familiar with the neighborhood character) and the residents belonging to the minor ethnic profile, felt unsafe compared to other residents. Additional studies of similar locations are needed to validate the influence of ethnicity and familiarity on fear of crime.

\section{Conclusion}

The objective of the research was to understand the influence of social and environmental characteristics on sense of safety in urban neighborhoods. Identifying such characteristics help planners and urban designers to acknowledge and understand factors generating fear or safety to create safe neighborhoods in the future. Fear of crime is a feeling of insecurity and anxiety that prevents the natural behavior of people in urban spaces. Though we may have not recognized this phenomenon, it defines the way we use or avoid specific places in the urban context. The study on Kotahena reveals that, fear of crime does not have a strong relationship with actual crime locations.

These research findings suggest that planners and urban designers need to improve visibility and design places to accommodate high density of people in town centers, streets and neighborhoods. Planners and architects also need to design places with a range of activities that function day and night. Mixed-use developments have to be an integral part of the landscape of urban neighborhoods. Issues related to underserved settlements need to be addressed through proper resettlement projects. Socio - cultural issues related to these underserved settlements need to be addressed through more inclusive and organized socio-economic policies. Economy empowering projects, social integration and rehabilitation programs need to be organized in multi-ethnic neighborhood areas and low income and underserved settlements.

Moreover, urban design guidelines to establish livable neighborhoods in terms of guidelines for the typology of buildings for varying land uses, conscious design of public spaces in the reuse of existing open and green spaces help re-vitalize existing neighborhoods. Active public spaces that are not blocked by fences and long boundary walls while reducing the possibilities of crime help create "places" for people by enhancing the overall spirit of the place.

It appears that Kotahena possesses characteristics that are observable in many of the general neighborhoods in the urban context of Sri Lanka. Thus the findings of this study could be used to 
have a better understanding of the design approaches needed to promote safe neighborhood streets by avoiding fear-evoking characteristics identified through the research. It needs to be highlighted that this study sample does not make the claim to fully represent the views of the wider population of Kotahena. The focus on a small resident cohort suggests caution in generalization. It was a small sample due the voluntary nature of the current research. The study findings, however, point to some general truths for the Kotahena area and similar urban settlements in relation to safety issues, and the influence of gender, density of activities and other environmental features in feelings of personal safety. The findings do not strongly show an association between feelings of fear and actual crime spots. Larger data sets would explore the nexus between fear of crime and crime hot-spots in greater detail.

Finally, as this research findings highlight, fear is associated with the lack of density of people in an area, visibility, types of surrounding neighborhoods, mono land uses, quality of people present, familiarity, gender and ethnicity. Considering the above findings, study does not suggest a unilateral planning approach to enhance feelings of safety. Rather a well-coordinated multi-faceted approach is needed in order to improve the sense of safety. Further, the findings suggest that feelings of insecurity are associated with diverse attributes in live settings and that these factors may vary depending on the urban fabric. Particularly, one important interpretation of the findings is that fear of crime needs to be understood holistically from diverse disciplines (planning, sociology, urban design, and criminology). These study findings suggest that further studies of this nature are needed in different settings with different demographic groups to support or reject the identified associations.

\section{Bibliography}

Australian Bureau of Statistics. (2010) Australian social trends: September 2010 (cat. no. 4102.0), Canberra, ACT, retrieved from http://www.abs.gov.au.

Appleton, J. (1975) The experience of landscape. New York: NY: John Wiley.

Crowe, T. (2000) Crime prevention through environmental design (2nd ed.). Boston-Butterworth: Heinemann.

Davis, M. (2006) Planet of slums. London: Verso.

Department of Police, (2014) Crime statisitics Sri Lanka, Police Head Quarters: Colombo.

Department of Census and Statistics Sri Lanka. (2013) Population and housing, retrieved from http://www. statistics.gov.lk.

Ferraro, K. F. (1995) Fear of crime: interpreting victimisation risk. New York: State University of New York Press.

Fisher, B., \& Nasar, J. L. (1992) 'Fear of crime in relation to three exterior site features: prospect, refuge and escape', Environment and Behavior, Vol. 24, no.1, pp. 35-65.

Fisher, B., \& Sloan, J. J. (1995) Campus crime. Springfield, IL: Charles C Thomas.

Foster, S., Knuiman, M., Wood, L., \& Giles-Corti, B. (2013) 'Suburban neighbourhood design: associations with fear of crime vesus perceived crime risk', Journal of Environmental Psychology, doi: 10.1016/jenvp.2013.07.015.

Goffman, E. (1971) Relations in public. New York: Basic Books.

Jacobs, J. (1961) The death and life of great American cities. Harmondsworth, Middlesex, England: Penguin Books Ltd, Harmondsworth, Middlesex, England.

Jorgensen, L., Ellis, G. D., \& Ruddell, E. (2012) 'Fear perceptions in public parks: interactions of environmental concealment, the presence of people and gender', Environment and Behavior, Vol. 45, no.7.

Kelly, E. (1986) 'What makes women safe?', Housing Review, Vol. 35, no.6, pp. 202-203.

Lagrange, R. L., Ferraro, K. F., \& Supancic, M. (1992) 'Perceived risk and fear of crime: role of social and physical incivilities', Crime and Delinquency, Vol. 29, no.3, pp. 311-344.

Massey, D. S., \& Denton, N. A. (1993) American apartheid. Cambridge, MA: Harvard University Press.

Mehta, V. (2013) The Street: a quintessential social public space. New York: Routledge.

Newman, O. (1972) Defensible space. New York: Macmillan.

Ratnayake, R. (2013)' Environmental features and sense of safety', WIT Transcactions on Ecology and The

Environment, Vol. 179, pp.377-388.

Ratnayake, R. (2013) 'Sense of safety in the Bendigo central business area', Proceedings of The Australian Sociological Association (TASA) Conference, Melbourne, Australia, November 26-28. 
Ratnayake, R., Silva, C., Warusawitharana, E. (2017). An examination of the temporal effects of environmental cues on pedestrians' feelings of safety. Computers Environment and Urban Systems, 64, 266-274.

Ratnayake, R. (2017). Sense of safety in public spaces: university students' safety experiences in an Australian regional city, Rural Society, 26(1), 69-84.

Ratnayake,R., Butt, A. (2017). Encounters with unfamiliar: International planning education. International Planning Studies, DOI10.1080/13563475.2017.1339347

Ratnayake, R. (2013). Fear of crime in urban settings: Influence of environmental features, presence of people and social variables. Bhumi: The Planning Research Journal, 6(1), 25-38.

Ratnayake, R. (2006). Gender and planning in Sri Lanka. Bulit Enviornment, 25(3), 28-39.

Warr, M. (1990) 'Dangerous situations: social context and fear of victimization', Social Forces, Vol. 22, pp. 891702.

Wilson, J., \& Kelling, G. L. (1982) 'The police and neighborhood safety: broken windows theory', The Alantic Monthly, March, pp. 29-38.

Yavuz, N., \& Welch, E. W. (2010) 'Addressing fear of crime in public space: gender differences in reaction to safety measures in train transit', Urban Studies, Vol. 47, no.12, pp.2491-2512. 